\title{
Memorias semióticas y fondos documentales: el caso 'Fondo Julio Cortázar'. Una lectura con Lotman
}

\author{
Semiotic memories and documentary collections: The case "Julio Cortázar Fund". \\ A reading from Lotman
}

\author{
Susana Gómez \\ sunygomez@gmail.com \\ Universidad Nacional de Córdoba, Argentina
}

Recepción: 11 Junio 2020

Aprobación: 24 Septiembre 2020

Publicación: 06 Noviembre 2020

Cita sugerida: Gómez, S. (2020). Memorias semióticas y fondos documentales: el caso 'Fondo Julio Cortázar'. Una lectura con Lotman. Orbis Tertius, 25(30), e163. https://doi.org/10.24215/18517811e163

\begin{abstract}
Resumen: Exploraremos hipótesis epistemológicas abiertas a partir de pensar los fondos documentales de escritor con nociones de Iuri Lotman. ¿Cómo reflexionamos sobre la textualidad en el sistema de un fondo centrado en la obra de un escritor? El sistema cultural, la memoria textual y la crítica sobre obras literarias poseen interesantes facetas que se conocen desde una lectura semiótica.

Palabras clave: Fondo documental, Semiótica, Memoria textual, Fondo Julio Cortázar ${ }^{1}$.

Abstract: We will explore epistemological hypotheses emerging from applying Iuri Lotman's notions to writers' archival fonds. How do we reflect on textuality within the system of a fond based on a writer's works? The cultural system, textual memory and the critique of literary works have interesting aspects best analyzed in a semiotic reading.
\end{abstract}

Keywords: Archival fonds, Semiotics, Textual memories, Julio Cortázar's Fonds.

La vigencia de la teoría lotmaniana ofrece lecturas que vienen en nuestra ayuda para considerar los cambios culturales que se han dado en este siglo, sobre todo por la circulación de grandes sistemas informáticos, considerando cómo la virtualidad se incorpora a la vida cotidiana y en la conformación de identidades y prácticas. Hoy comprendemos cómo los procesos digitales en el desarrollo de redes veloces de tránsito de la información, así como los procesos globales que se vuelven simultáneos, dan lugar a su vez a subjetividades y nuevos roles digitales que no poseen cuerpos físicos sino numéricos, entidades tales como los avatares y las identidades ficcionales en redes sociales. En estos momentos, la noción de "hipertexto" está siendo reemplazada por nuevas metáforas en que "digital" pareciera ser el lugar común u objeto de base para sustituir los viejos procesos en las nuevas formas de actuación sobre los depósitos de datos que es la cultura escrita.

"Digital" supone el dígito (una categoría matemática que sostiene todo el aparato de la informática) pero también el dedo que cliquea y pone en movimiento el sistema entero donde este acto de lectura se ejerce. Con ello, la renovada discusión sobre la memoria y el archivo, en especial sobre la puesta en línea de textos como derecho en el acceso al conocimiento, suponen un traslado epistémico entre formas de la cultura escrita, el acervo de archivos en papel vueltos digitales y la creación de nociones diferenciales para observar estos procesos de oferta de lo textual a los lectores en su consulta en la web sin mediar ya el espacio geográfico 
ni el tiempo de espera como condicionantes. Hemos logrado capacidades de acceso, pero hemos creado condicionamientos específicos ante la acción y las prácticas que producen el sentido del sentido en prácticas de diseño de acciones o de procesos (Dondero, 2015, p. 117). ${ }^{2}$

En "La memoria a la luz de la culturología", se lee un interrogante planteado por Iuri Lotman que tiene hoy -como muchos de sus textos- una sorprendente actualidad.

A lo largo de toda la historia de la cultura, constantemente se hallan, se descubren, se sacan de la tierra o del polvo de las bibliotecas, monumentos "desconocidos" del pasado ¿De dónde salen? [...] Cada cultura define su paradigma de qué debe recordar (esto es, conservar) y qué ha de olvidar. (Lotman, 1996 [1985], p. 159)

Esta cita funciona como la palabra maestra que posibilitará dar cuenta de cómo su pensamiento ofrece alternativas en espacios y modelos de investigación poco conocidos o no reconocidos como tales. Tal es el trabajo de diseñar un sistema de ordenamiento, rescate y puesta en valor de un fondo documental. El Fondo Julio Cortázar, en la Universidad de Poitiers, digitalizado nuevamente manteniendo su primer diseño informático de catalogación, viene a ser el caso en que situamos aportes de su teoría, quizá impensados para él. ${ }^{3}$ Este Fondo fue catalogado primero en 2008 y en 2011 se coloca en la web en un formato que permitía conocer de manera lineal y vertical los documentos en él resguardados (cerca de 1700 documentos). Pero el sistema informático caduca y en 2019 comienza a trasladarse a un nuevo sitio web donde se reorganiza su visualización a partir de la anterior pero generando una ubicación en capas. Este nuevo diseño, ya se separa de su materialidad física en carpetas-biblioratos situadas en un armario físico con números consecutivos y folios ${ }^{4}$ con los papeles, otorga otra densidad y da lugar a una horizontalidad de localización, en que cada capa de datos provee a su vez todos los que identifican a un documento. Se abre el sitio web y las solapas reenvían en despliegues a diferentes modos de acceder a ellos, según la capa de datos en que se hallen: carpetas, títulos, autores, fechados, colecciones y un buscador expande aún más estas posibilidades de que el documento halle su lector. ${ }^{5}$

De este modo, un desarrollo técnico produce otros formatos para conocer aquello que estuvo disperso y que sería imposible tener frente a la vista en la época analógica en que se publicaron o se redactaron los documentos. Nos preguntamos con Lotman de dónde "salen", qué origen les da lugar y porqué preservarlos involucra también su "apertura" (una metáfora, igual que usamos la navegación para señalar cómo nos movemos en el espacio de la web). Abrir un fondo documental ratifica nociones que Lotman nos había enseñado, aquellas ligadas a la cibernética, pero antes que eso a una serie de nociones/figuras cuyo punto central es la memoria. Nos preguntamos acerca de qué responsabilidades se ven implicadas en su diseño, reconociendo que este deriva de operaciones mentales que rodean al actuar en un mar de documentos. Asimismo, qué incidencia tiene el texto documental publicado en papel pero subido a la pantalla, en tanto es propiciador de un uso lógico particular de los lenguajes en segundo grado que son los textos informáticos que "devuelven a la vista" del usuario aquellos lenguajes primarios de una crítica, un dibujo o una fotografía.

El aporte de la teoría de Lotman (y de la Escuela de Tartu) habilitó nuevos conceptos para pensar estos procesos de cambio digitales del FJC. En el momento inicial de su diseño, sus perspectivas basadas en la cibernética de los años setenta y ochenta permitieron salir de nociones cerradas y sostenidas fuertemente en una horizontalidad diacrónica -el tiempo como una línea), así como de la necesidad de clausurar una cronología o de inscribir los documentos en un plano fijo con datos (la catalogación abre dimensiones pero el documento debe quedar situado en un punto estable). Además, motivó comprender otro sentido al establecimiento de cada documento en una "serie", colección o grupo de textos que derivaba siempre en una taxonomía que, por otra parte, necesitábamos para ofrecer la certeza de su origen, la claridad de su presencia en el campo crítico sobre Cortázar. Se impone una consideración del tiempo ya no como duración sino lo que el propio Lotman llama "pancronicidad" (Lotman, 1996 [1981], p. 93) al hablar de un segundo enfoque para la noción de texto, consistente en pensar un texto como "formación finita, delimitada, cerrada en sí misma" (ibid, p. 93) que ofrece una arista interesante: la vinculación entre texto y lenguaje inscribe un tiempo interno 
propio, que produce sentido en su relación con el tiempo natural. Hablamos de una integración de marcos temporales diferentes en cada lectura de los documentos, además marcados por las fronteras finitas de cada texto del archivo que conforma el FJC u otro Fondo de escritor. Por otra parte, ese mismo texto inmanente allí donde parece cerrarse su organización, se vuelve abierto a interpretaciones y, por ende, se afirma como inconcluso.

En esta reflexión sobre la temporalidad descubrimos algo en común entre Cortázar y Lotman: una preocupación por el tiempo, por la situación de los textos y de la cultura de cara a un futuro que es siempre colocado en sus escritos como una prospectiva. En Cortázar, leemos anotaciones que indican una particular reflexión sobre la temporalidad. ${ }^{6}$ Lotman, por su parte, habla en presente en nuestra cita -si la traducción es fiel y confiamos- para señalar el constante descubrimiento de textos en la memoria de una cultura, como lo es para nosotros esta anotación manuscrita que pareciera reunir una compleja red semiótica de consideraciones acerca del tiempo. Cómo conciben el tiempo ambos autores ilumina el proceso de diseñar un Fondo de Escritor. Nos inspira una traslación epistemológica que resulta fundadora de otras lógicas para pensar el sistema de su diseño informático en una red de textualidades pancrónicas (e intensas, como indica Cortázar) donde la partición lineal del tiempo en tres instancias (pasado, presente, futuro) se vuelve un plano textual en que la memoria cultural se nos ofrece como un espacio semiótico. Recordemos que Lotman, en el texto que citamos propone reemplazar "largo/corto" por diversas intensidades y velocidades para la transformación de una cultura, para su producción autorregulada en que el arte es ejemplo central. Con ello, organizar un conjunto de papeles pertenecientes a un escritor también implica encontrar el sistema autorregulador que permita incluir la memoria en su devenir informático.

Subrayamos de la última frase en la cita que inicia este artículo, donde se indica que "cada cultura define" qué documentos o textos resguardar para que sean recordados, en tanto es una "inteligencia colectiva y una memoria colectiva”. De este modo, cada cultura propone para sí un modelo de selección y de recordación. Tal es el paradigma regulador de modos de pensar y de sentir la temporalidad en que se crean, y resuelve cómo se decide que perduren.

Otro artículo iluminador de Lotman es "Discontinuo y continuo", donde refiere a los procesos explosivos en la cultura y a cómo el estructuralismo tradicional pasaba por alto su carácter dinámico al considerar al texto como "sistema cerrado, autosuficiente, organizado de manera sincrónica" y, ante esto, propone revisar esa idea para recuperar el tiempo como factor central en la existencia de los textos:

En el tiempo, el texto es percibido como una imagen establecida sui generis, un momento fijado artificialmente entre el pasado y el futuro. La relación entre estos no es simétrica. El pasado se deja aferrar en dos manifestaciones: en la memoria directa del texto, encarnada en su estructura interna, con su inevitable contradicción, en la lucha inmanente con el sincronismo interno, y externamente, como correlación con la memoria textual. (1999, [1993], p. 27)

En el FJC vemos claramente que esta doble valencia de lo temporal en los textos orienta tanto la organización interna de los documentos en su lugar en una carpeta, o una cronología obligada por las regulaciones bibliotecológicas y archivísticas -a su vez memoria cultural, con su valor y su justificación en tesauros internacionales -, como este otro aspecto señalado recién: una correlación en la memoria en un entorno textual. Tal entorno genera una indicación con respecto a que los contextos -históricos en este casono son ajenos ni exteriores sino que se inscriben en el mismo texto desde su origen. Cada documento del Fondo genera su propio contexto, lo crea para el sistema de búsquedas pero también para su producción de sentido; ya que no es posible -desde Lotman- pensar una existencia externa o precedente al texto mismo, que resultase separable de él; menos aún al situarlos en un sistema informático de archivos virtuales, ya que ese contexto se vuelve en segundo grado significativo de cada documento. ${ }^{7}$

Hilos de Ariadna (o Ariana), mapas del metro subterráneo parisino o porteño, encuentros del azar entre los amantes, la obra de Cortázar se torna metáfora de sí misma a la luz de este planteo lotmaniano en que percibimos la relatividad e inconsistencia del tiempo en el presente siempre renacido en que cada texto es 
convocado y leído. Llama la atención la formación de las carpetas que inicialmente crease Gladis Ancieri: los títulos de las obras son la base para clasificar los documentos, pero en ellas, se impone la cronología por necesidad física de ordenar cada uno de ellos. Luego, el sistema informático produce, como en la cultura, un estallido que reubica en la pancronicidad cada documento.

Excedemos aquí la apreciación lotmaniana, porque él se refiere a las obras literarias y al arte, para desplazar su concepto al diseño - proceso inacabado tanto en lo archivístico como en la recepción posible- de un Fondo Documental por lo que tiene de creativo y, exagerando, de "estallido de espacio no desplegado" (1999, [1993], p. 29).

Una obra en singular, la de Cortázar, se produce en muy disímiles interacciones culturales que la dinamizan, que le dan con ello un movimiento en entornos culturales más amplios. Entonces, los textos que derivan de ella también son proclives a tal dinamismo, así como a una igual manera de resguardar en sí mismos su propio germen de futuro. Un paradigma capaz de otorgarle singularidad a cada texto individual en el recorte de un hacer y saber comunes a la cultura en que se desvela y muestra. El arte ofrece en segundo grado componentes que son receptados por los textos críticos (el conjunto de la crítica y sus recorridos recurrentes) para ser devueltos a un habla primaria, a un lenguaje primero en que comentamos, intervenimos, entrevistamos, transcribimos otros textos.

Podemos acudir a la idea de un modelo - la declinación, las formas verbales- o de una regla de producción e intuimos, también sería un elemento regulador inherente a la propia cultura para el resguardo de sus textos como codificadores de la memoria. El paradigma sobre el que se recorta la decisión de guardar implica un modelo del tiempo, del pensar la memoria en prospectiva por definición. ¿Qué es la memoria sino una prospectiva silente de sus textos?

La conservación de la que habla Lotman, no sería en este caso ya un reservorio material, físico en carpetas azules por ejemplo, conteniendo recortes de periódicos doblados por la mitad con sus correspondientes marcas a lapicera roja o morada. "Conservar" atiende a la textualidad inscripta en ellos por fuera del lenguaje verbal: es texto -dispositivo pensante- también aquel disperso en otros espacios de la cultura que son receptados por las palabras del escritor o del crítico, atendidos en su in-materialidad semiótica, su presencia en la mente y el recuerdo de la colectividad.

Nos atrevemos a decir que la selección de aquellos textos o documentos para su resguardo futuro, por parte del propio Cortázar, trasciende el individuo en una decisión solitaria como lo sería la elección de un tema para narrar o una anécdota; lo involucra en tanto que participa de la colectividad, del común en que se crean los textos/documentos.

Por ejemplo, el cuento "Los amigos" sale editado en una revista cultural del diario La Prensa de San Salvador en 1965 y luego lo encontramos en idioma ucraniano en una revista de 1974, donde anuncia la aparición de Final del Juego. ${ }^{8}$ Igualmente, vemos como una figura metonímica de la literatura cortazariana, en el cuento "Shine, shoshine, shoe shine boy" -título original en inglés- al pequeño lustrabotas de Bombay que canta mientras lustra los zapatos de este narrador en primera persona, que reconocemos como el otro yo de Cortázar. Este segundo cuento figura en una carpeta de fotografías de las diferentes ediciones casi simultáneas en 1970, publicadas en revistas y periódicos en diferentes idiomas, pero recién se publica en libro de manera póstuma en Papeles inesperados, en 2014. Nos preguntamos: ¿Quién preserva qué habla, la del cuento policial que dura lo que un atraco o acaso es la India atestada de pobres la que dibuja un mismo mundo desde la palabra modélica de un narrador asustado por la probabilidad de que le arruinen los zapatos de gamuza con betún? Tales los textos, así se oyen en el FJC referidos en un tercer grado del metadato necesario para "colgarlo" (otra metáfora) de la percha que lo hace elegible por un clic de un usuario.

Volvemos a la cita de nuestro incipit: "qué debe recordar", dice Lotman. Ese objeto recordable ratifica su presencia constante a posteriori en la vida cultural y en la producción de nuevos textos, lo cual implica también una decisión y un reparo a la inclemencia de los cambios y del tiempo: "esto es, conservar", como 
coloca entre paréntesis. Regla del paradigma, ley de la obligatoria tarea de constituir un texto mnemónico, un recordatorio que es a su vez, un nuevo texto.

Cada texto, sabemos, traduce y se reúne con el anterior y con el subsiguiente, pero a su alrededor hay otros procesos similares. Traduce en una lengua a otra, traspasa las fronteras del texto/dispositivo pensante migrante por un espacio virtual. Trasluce, además, qué se ha resguardado al recuperarlo en la pantalla. Retoma al presente perenne el pasado de su producción y anticipa futuras lecturas, que se dejan plausibles para cuando vuelva a leerse. He ahí la "actualidad" que toman muchos documentos del FJC, como las entrevistas al autor, en una colección de memorias de hablas, de lenguajes de época y de circunstancias que vuelven a ser perceptibles, dinamizando con ello la lectura investigativa de la obra y trayendo al interés de los lectores de a pie un personaje singular.

Intento resumir algunos postulados lotmanianos interviniendo en la organización del FJC en esta tríada de nociones; traducir, traspasar y traslucir como movimientos que toda significación requiere para ser parte del registro a conservar que, en prospectiva, será necesario en la unidad cultural que se vive o vivirá, indefectiblemente. En la Historia no somos nada sin textos, vieja máxima de los historiadores, porque los textos son a nosotros como la historia a sus acontecimientos cotidianos, ínfimos que se rescatan en el relato de la existencia en la vida social.

Cada documento del FJC remite a un momento o un acontecimiento que muta en otro cada vez que es leído; con ello, habilita acontecimientos nuevos que se superponen y mixturan con los anteriores. Tal es el caso de las polémicas literarias que se reúnen en in-feliz ocasión al verse sus textos remitir a otros, palabras sobre palabras que hablan de formas de percibir e imaginar el mundo, de volcar esta percepción en la existencia de otro estatuto que son las ficciones. Entre ellas, la polémica obra Libro de Manuel. Ocupa la Carpeta 18 pero el buscador despliega por citaciones por la aparición del título en otros lugares del Fondo. Vemos cómo un crítico literario argentino no ha leído la novela pero igualmente la rechaza de plano. ${ }^{9}$ Rechaza su signo/novela, por la destinación de los derechos a causas políticas y eso le resulta suficiente para desmerecer una obra. Este acontecimiento en la vida del texto (el que se titularía: "lo que se dijo sobre Libro de Manuel que la gente se atrevió a pronunciar") está presente en esa serie al infinito de lenguajes y metalenguajes verbales, numéricos e informáticos. Al técnico de computadoras que programa la base de datos (no otra cosa que una lengua artificial que interpreta y a su vez traduce, traspasa y trasluce) no le interesa este acontecimiento que enlaza una obra literaria (en segundo grado, un Manuel y un grupo de adultos, pingüinos fucsias y peludos reales) con su referencia literaria, sino la sola presencia de los textos en una invisibilidad del dato en un lenguaje artificial, doblemente un código.

La pregunta constante es: “Este código, este número, ¿está?”. Si está bien o mal ubicado, si falta una hoja, si el autor está mal escrito o es el mismo que otro texto, no le interesa en absoluto. Su lenguaje artificial reconoce otras referencias y no sabe -no le interesa, insisto- que son semióticas también. Lo dice Lotman, antes de que se inventara la web y Cortázar lo imaginó con su máquina Rayuela, con su recortar y pegar de sus libros miscelánicos y en la metáfora recurrente de "la gota que tiembla adentro de un cristal" en sus variadas formas de escritura, ese imponderable imaginativo.

Percibimos con curiosidad la lista de verbos de la cita central en este trabajo, hilando fino: definir, recordar, conservar y finalmente, olvidar. Los pasos no oponen el recuerdo al olvido, sino que se los inscriben en una particular organización en que ambos son proceso y resultado de una presencia de los textos en la dinámica de la cultura. Textos fundantes, formadores y a la vez legado ("polvo de bibliotecas").

Tomamos dos aspectos que devienen de esta reflexión: por un lado la presencia de la transmisión, concepto que en su interior supone un traspaso temporal, una incorporación de procesos culturales de diferente duración que dinamizan los textos (documentos en este caso) frente a los cambios culturales y, por otro lado, que este traspaso no es trabajo de los individuos sino de la cultura en sí. Es ella la que desarrolla sus propias estrategias de definición-conservación-transmisión, habida cuenta de que los textos en sí mismos parecen tener menos importancia que aquello de lo cual son portadores. Dice Lotman en "La memoria a la luz de la 
culturología", pensando en la memoria como una inteligencia colectiva, que en su interior es enormemente variada:

Así pues, la memoria común para el espacio de una cultura dada es asegurada, en primer lugar, por la presencia de algunos textos constantes y, en segundo por la unidad de los códigos o por su invariancia, o por el carácter ininterrumpido y regular de su transformación. (Lotman, 1996 [1985], p. 157)

Los textos a los que atendemos, implican también una superación del concepto estructural de texto/unidad de significación, ya que en la propuesta semiótica de Lotman un texto cultural atraviesa unidades/signo o materialidades y, con ello le da seguridad de transmisión.

Venimos diciendo que un texto constituye un sistema de conjuntos de sistemas extratextuales que le dan condición de existencia, cuya organicidad está supeditada a su presencia a través de lenguajes en la cultura y no sólo en un formato o un recorte material (una novela o un cuadro, un pin que vendría a ser como las medallas en la época de los zares, que estudiaran los del grupo del Tartu). La presencia del texto, entendido en sus funciones de cumplir la destinación de un mensaje en una memoria cultural, siendo esta la función más importante ya que el destinatario "trata" consigo mismo, le permite vincularse a estas estructuras culturales amplias en que pervive como receptor. ${ }^{10}$ Por ende, la presencia del texto en un espacio cultural es también amplio pero no por ello ilimitado.

Esta operación teórica se puede ver a través de un Fondo documental como este, y tantos otros, entre ellos un archivo de un hospital o de un juzgado. Cada texto (por caso: las patologías y su sanación en "La señorita Cora" como invariante cultural que emite textos/receptores de comunicación de, por ejemplo, un mandato bíblico) inscrito en ese archivo, datado y marcado para su localización, abre interrogantes memorísticos en un espacio limitado de la cultura. La obra de Cortázar está fortalecida por el trabajo memorioso de la crítica y la prensa, por la analítica que cimenta un artículo en una revista universitaria. Sí, pero en eso no radica la presencia de un texto en la cultura. No son estos los textos que se "define guardar" en ella. Los documentos del FJC están empapados de relatos sobre el mundo, de arqueológicas formas de percepción de lo real (el fantástico) o simplemente de flores amarillas, de cuellos suaves de mujer en el metro o de juegos infantiles congelados en metáfora creadora de una novela; Ariadna es Ariana enamorada y los castillos sangrientos llevan a una red de significaciones sociales ligadas a la muerte caníbal, o la infancia es una moratoria vital de un niño llamado Manuel que deberá leer -cuando aprenda- qué fue de sus padres quizás hoy desaparecidos o muertos.

La cultura tiene su límite, lo cuida y lo asevera para la propia transmisión época a época. La constancia de la que habla arriba, entendida en esos términos, implica pensar que podemos hallar textos culturales en lugares que insospechadamente reciben una estructuración en la colectividad que la crea al receptarla o comprenderla, que le da dinamismo creador. Nos recuerda otra cita de Lotman que indica en "la semiótica de la cultura y el concepto de texto" que éste sería: "un complejo dispositivo que guarda variados códigos, capaz de transformar los mensajes recibidos y de generar nuevos mensajes” (Lotman, 1996 [1985], p. 82)

Un Fondo documental redunda en dispositivo, pensamos ahora. Un mecanismo de resguardo pero también un sistema productor de un modo de resguardar: pienso en la catalogación, en los acuerdos históricos con respecto a qué considerar ("definir") un autor, un año, un dato editorial. Por ende, el dispositivo crea maneras de guardar las instrucciones del pensar mnemotécnico. Este mismo que se halla en otros sitios en la cultura: otras bibliotecas, los archiveros, las bibliografías y los catálogos editoriales que por siglos "definieron" autor, año, título, edición, lugar. Pero antes que nada, se encuentran en la propia memoria de los individuos, en su memoria táctil, en su memoria afectiva, en sus redes cognitivas que les motivan el imaginar, que alientan la escritura de una nueva obra. ${ }^{11}$

El sistema de la cultura es una ingeniería de la memoria, podríamos decir. No una simple proliferación de textos u objetos textuales que fuesen portadores de una cierta significación -con Lotman aprendimos a relativizar absolutos de sentido. Por ello, las nociones se oyen como el sonido de una maquinaria funcionando 
en largos períodos de tiempo, aunque no ininterrumpida. La memoria, entonces, no es un reservorio, sino un mecanismo productor de signos cuya combinatoria constituye la cultura. Mientras más textualizada es una cultura (independientemente de su materialidad en escritura o formas de codificación), más complejo y económico es el funcionamiento de su potencial de memoria.

Una semiósfera se constituye de este modo, en una combinación de economías del recuerdo, de lo olvidado y de la temporalidad inscripta en ella. La legibilidad de los textos culturales es una feliz resultante de estos procesos de la semiósfera, ya que autoconstruye sus propias gramáticas de generación-resguardo/olvido. Un fondo documental digitalizado en la web viene a ser, según mi lectura de Lotman, un ejemplo del funcionamiento de la semiósfera. Dice Lotman, al respecto: "La diversidad interna de la semiósfera presupone la integralidad de esta. Las partes no entran en el todo como detalles mecánicos, sino como órganos de un organismo" (Lotman, 1996, p. 32), que precisa tanto de partes como del isomorfismo, aquella capacidad de generar un aumento de los mensajes porque son a la vez parte de un todo y semejantes cada uno a ese todo.

Así, el sistema de catalogación / digitalización es capaz de convertir el texto en "una avalancha de textos" (Lotman, 1996 [1985], p. 32) que no son los nuevos, ya que otro es su mecanismo productivo, dados por los intercambios. Por eso, recuperamos el concepto de frontera, ya que si bien este Fondo Documental está cerrado, su jerarquizacón es vertical e interna, su avalancha de textos en el interior de lo que se resguarda en Poitiers ha cedido el lugar al proceso exterior y ulterior de utilizarse para la búsqueda de datos y de una historicidad cuyos nuevos textos ya están fuera de los límites del fondo, en otro funcionamiento diferente de los textos en que la diferencia (otra forma de isomorfismo) pesa más. Radica allí un diferencial de significación marcado en otra época en que estos textos se publican pero, en tanto son también una comunicación para receptores nuevos, producen otra significación. El FJC cumple su rol como ejemplo pero también como imagen (un tropo) del legado. ¿Habría pensado en ello Cortázar cuando decide donar a las universidades sus papeles, vendiendo primero los manuscritos a Texas y luego esto? El traslado de los materiales físicos (las carpetas, para entendernos) implicaba también un traslado en ese mundo extrasemiótico que Lotman señalara, de la realidad, traducido a otro lenguaje, esta vez, el informático.

Quisiera dejar señaladas aquí algunas consecuencias de la observación del Fondo Cortázar a partir de la perspectiva de Lotman, en su enfoque semiótico que -motivado por la aparición de la cibernética y luego la informática en los años 60 y 70, hasta llegar a sus últimos trabajos. Es posible reconocer que conllevan a la comprensión de una mirada epistemológica sobre un hacer investigativo con Archivos de Escritor y Archivos Virtuales que excede las prácticas demostrativas y abandona un conocimiento cómodo, aquel en que nada se afirma sino que se ofrece al otro sólo como una posibilidad de re-verificación.

Y en segundo lugar porque el pensamiento de Lotman - que consideró en su momento a la naciente cibernética- permitió salir de los estables tablones en que pretendemos cruzar de un edificio a otro en la cultura de los archivos abiertos en la era digital global. Remitimos a esta metáfora en la comprensión del capítulo de Rayuela tan conocido (el capítulo 41) en que se intenta trasladar un paquete de yerba, cruzar con ese contenido en las alturas por comodidad, por juego y, finalmente por absurdo. Con ello, pretendemos explicitar cómo se logró constituir un archivo de documentos -este, quizá otros- en especial involucramiento de las nociones de memoria -siempre común, colectiva aunque requiera de un acto de recordar individualy de textos en tanto portadores de significación que pudieran estar dispersos en un recorte cultural, de una época, un nombre propio de autor como Cortázar y una reunión de metatextos, y ese conjunto sistémico de signos conformadores de un "archivo". Por ejemplo, la bibliografía es un modelo textual de identificación de textos que pudieron estar repartidos por el mundo pero de pronto encontramos reunidos en una colección.

¿Cómo definió la cultura cuáles textos culturales estarían presentes y actuantes en un conjunto documental coleccionado por quien operaba de manera inaudita con ellos? ¿Es por eso que se busca ordenarlos, clasificarlos; por ser reserva y resguardo en un espacio cultural llamado literatura?

Diseñar el Fondo Julio Cortázar requirió pensar en la noción de migración semiótica que llevaba/traía palabras clave o descriptores libres. Elegirlos recaía una y otra vez en la conformación de un repertorio de 
temas, de lugares comunes (topoï), de retóricas compartidas (el género, la metáfora de los títulos, el tropo central de la crítica y la imagen intertextual que, basada en la obra de Cortázar daba lugar a muchos "nudos temáticos" de la prensa y crítica, o de las entrevistas).

Investigar ese Archivo como un arché, un arcaísmo (vivo, diría Bajtín, que sería cada documento) y a la vez un alerta y elogio al anacronismo. Un arché, que remeda a arqueología y con ello a colección, haciendo las veces de indicador de huellas de sistemas codificantes (que siempre modelizan el mundo porque devienen de él) que un informático (un técnico en un metalenguaje) debía reconocer, interpretar y luego, traducir en un otro sistema. Colocar las palabras clave (palabras-llave les nombré en su momento, capaces de abrir el archivo en múltiples cerraduras) involucraba crear textos de textos de textos al infinito. Un término tal como "literatura latinoamericana", habría otra entrada en las palabras claves como "Latinoamérica" y esta, a su vez, por ejemplo, "boom". En entrevistas a Cortázar sabemos que, como escritor que leía sus reseñas, no se reconocía en esa corriente de los años sesenta y debatía fuertemente críticos al respecto. Este detalle derivado de la inscripción de descriptores en la indización del FJC, pone de manifiesto una huella de un proceso textual compuesto por todos los textos críticos, en el conjunto por su colectividad, su memoria teórica y retórica, su dicción y sus dispositivos descriptivos/persuasivos). Así como vemos una red implícita en este conjunto textual disperso, observamos que funcionaba cada artículo referido a "Boom" como texto/clave y textos/llave, que permiten decodificar y habilitar el encuentro de un artículo o una tesis doctoral por parte de un usuario.

En fin, hablamos de un cuerpo de significación que sólo pudimos pensar gracias a la tecnología de las bases de datos y a que somos capaces de pensar en términos de bases de datos porque la cultura las ha incorporado a nuestra vida diaria. Por ende, pensamos en el Fondo a través de esta visión lotmaniana que convoca la consideración de un conjunto orgánico de textos cuya codificación establece un mecanismo estructurante interno: se reenvía a sí mismo, motiva reenvíos entre los componentes del sistema de la catalogación y, finalmente se constituye como texto "Cortázar" desplegado en la multiplicidad de los más de mil documentos.

¿Supo Cortázar quién reuniría esta pequeña memoria cultural sobre su obra, guardando en cajas cuanta cosa saliera publicada o le enviaran sus amigos e instituciones? ¿Es en la cultura-memoriosa de su propia complejidad, ese tejido todo junto- donde reposa la obra de Cortázar, permitiendo su interpretación/ traducción por individuos/técnicos que nada saben de él y sin embargo leen sus datos? ¿Es la base de datos un sistema modelizante en sí mismo, una estructura en segundo grado que deja insonoras las funciones del texto cortazariano y, a la vez, las vuelve audibles en la telaraña documentos del Fondo Cortázar albergados en la web?

\section{REFERENCIAS}

Dondero, M. G. (2015). Semiótica de la acción: textualización y notación. Tópicos del Seminario, 33, enero-junio 2015, 101-130.

Lotman, I. (1996 [1985]). La memoria a la luz de la culturología. En Lotman, I., Semiosfera I. Valencia: Frónesis. [Trad. Desiderio Navarro].

Lotman, I. (1996 [1981]). La semiótica de la cultura y el concepto de texto (Tartu). En Lotman, I., Semiosfera I. Valencia: Frónesis. [Trad. Desiderio Navarro].

Lotman, I. (1999 [1993]). Cultura y explosión, Barcelona: Gedisa. [Trad. Delfina Muschietti]

Lotman, M. (2013 [2002]). “Umwelt y semiosfera” Mijail Lotman Fuente: Sign Systems Studies 30.1. En Hoffmeyer, J. et.al., Semiótica de la cultura, ecosemiótica, biorretórica (pp. 33 a 40). Córdoba: Facultad de Lenguas UNCórdoba. 


\section{Notas}

1 El Fondo Julio Cortázar se crea en el Centre de Recherches Latinoaméricaines -Archives (CRLA-Archives) en la Universidad de Poitiers, Francia. Hoy cargado en una nueva plataforma, se conforma de casi 2000 documentos de prensa y crítica que pertenecieron al escritor y que se catalogaron para crear las bases de datos en Archivos Virtuales Abiertos (Open Access) en 2011. Con ello se desarrollan elaboraciones críticas y teóricas acerca de los Archivos Digitales, en el diseño y puesta en línea, aprovechando conocimientos que provienen tanto desde los estudios literarios -en este caso semióticos- y archivístico-informáticos. Consultar en: https://cortazar.nakalona.fr/

2 Dondero trabaja una semiótica con Fontanille, postulando una metodología de observación de procesos de diseño en arquitectura que, incluso usan mesas digitales donde las notaciones "quedan" fijadas y pueden luego relevarse. Nos sirve este artículo para pensar los diseños de archivos de escritores, también colaborativos y de intersecciones de prácticas semióticas.

3 De ahora en más FJC

4 En Argentina se denomina así a bolsitas de polipropileno con margen perforado que pueden ser encarpetadas. Sin embargo, en la terminología archivística, "folio" se utiliza para hoja a numerar consecutivamente.

5 Los documentos que forman el Fondo Cortázar, fueron cedidos al Centre de Recherches Latino- Américaines-Archives, en la Universidad de Poitiers por el propio autor a partir de la organización que le encargara a Gladis Anchieri en 1981. Las cajas de supermercado en que se transportaron al departamento del matrimonio Anchieri-Yurkievich, establecían una historia de la obra de Cortázar impensada en ese momento. En 2019, Gladis cede más papeles que pertenecieron a su esposo Saúl Yurkievich y ya están incorporados al Fondo en su nueva instalación sita en https://cortazar.nakalona. fr/ en la plataforma Huma-Hum, Francia.

6 Leemos en el "Cuaderno de Bitácora de Rayuela" a mano lo siguiente:

"El tiempo

Como duración.

Como condensación (en el sueño)

En las mutaciones animales: (de Vries): el tiempo como intensidad” (p. 33: anotada por Ana María Barrenechea)

7 Un trabajo donde se dialoga acerca de los entornos y la noción de contexto está en «Umwelt y semiosfera», de Mijail Lotman publicado en Sign Systems Studies 30.1 (2002), pp. 33 a 40. En Bibliografía citaremos la traducción en Semiótica de la Cultura / Ecosemiótica / Biorretórica (UNC, Córdoba, 2013, p. 197)

8 "Los amigos", ficha \#1246 y \#447 respectivamente, en el FJC (ver link en nota al pie 3)

9 Es la famosa discusión del primer número de la revista Crisis en 1973, donde debaten Raimundo Ongaro, Liliana Heker y otros; allí se publica una breve anotación del Padre Mujica, quien dice no haberla leído ni pretender hacerlo porque no la acepta.

10 El texto es un receptor de textos, en la teoría de la Escuela de Tartu.

11 Es interesante ver la cantidad de obras escritas a la luz de las cortazarianas, así como la proliferación ( por ello utilizamos con Lotman la metáfora de la explosión) de citas, blogs, sitios de internet, de duplicados y de la presencia en la cultura de los aportes de Cortázar por generaciones: los cronopios y famas, las Magas, las morellianas. O cómo se recuerda la masacre de Trelew de 1972 en la dedicatoria de Libro de Manuel, sus cuentos en filmes, etcétera. ¿Cuál será entonces la figura retórica que designa a esa reduplicación en espejo de texto a texto, sistema a sistema, dato a dato al infinito? Son archivos, serán arché pronto. 